NBER WORKING PAPER SERIES

\title{
CARBON PRICES AND AUTOMOBILE GREENHOUSE GAS EMISSIONS: THE EXTENSIVE AND INTENSIVE MARGINS
}

\author{
Christopher R. Knittel \\ Ryan Sandler \\ Working Paper 16482 \\ http://www.nber.org/papers/w16482
NATIONAL BUREAU OF ECONOMIC RESEARCH
1050 Massachusetts Avenue
Cambridge, MA 02138
October 2010

This paper is a contribution to the NBER conference on The Design and Implementation of U.S. Climate Policy, May 13-14, National Press Club, Washington, DC. We thank Matthew Kotchen and Catherine Wolfram for helpful comments. We gratefully acknowledges financial support from the University of California EEE. Knittel gratefully acknowledges financial support from the Energy Institute @ Haas. The views expressed herein are those of the authors and do not necessarily reflect the views of the National Bureau of Economic Research.

NBER working papers are circulated for discussion and comment purposes. They have not been peerreviewed or been subject to the review by the NBER Board of Directors that accompanies official NBER publications.

(C) 2010 by Christopher R. Knittel and Ryan Sandler. All rights reserved. Short sections of text, not to exceed two paragraphs, may be quoted without explicit permission provided that full credit, including (C) notice, is given to the source. 
Carbon Prices and Automobile Greenhouse Gas Emissions: The Extensive and Intensive Margins

Christopher R. Knittel and Ryan Sandler

NBER Working Paper No. 16482

October 2010

JEL No. L0,Q5

\title{
ABSTRACT
}

The transportation sector accounts for nearly one third of the United States' greenhouse gas emissions. While over the past number of decades, policy makers have avoided directly pricing the externalities from vehicles, both in terms of global and more local pollutants and Corporate Average Fuel Standards have changed little since the mid-1980s, there is now considerable interest in reducing greenhouse gas emissions form the transportation sector. Many have argued that the unique features of the sector imply that pricing mechanisms would have little affect on emissions. This paper analyzes how pricing carbon through either a cap and trade system or carbon tax might affect greenhouse gas emissions from the transportation sector by estimating how changes in gasoline prices alter consumer behavior. We analyze their effect on both the intensive (e.g., vehicle miles travelled) and extensive (e.g., vehicle scrapping) margins. We find large effects on both margins.

\author{
Christopher R. Knittel \\ University of California, Davis \\ Department of Economics \\ One Shields Ave \\ Davis, CA 95616 \\ and NBER \\ crknittel@ucdavis.edu \\ Ryan Sandler \\ University of California, Davis \\ Department of Economics \\ One Shields Ave \\ Davis CA 95616 \\ rsandler@ucdavis.edu
}




\section{Introduction}

The transportation sector accounts for nearly one third of the United States' greenhouse gas emissions. While over the past number of decades, policy makers have avoided directly pricing the externalities from vehicles, both in terms of global and more local pollutants and Corporate Average Fuel Standards have changed little since the mid-1980s, there is now considerable interest in reducing greenhouse gas emissions form the transportation sector. Many have argued that the unique features of the sector imply that pricing mechanisms would have little affect on emissions.

This paper analyzes how pricing carbon through either a cap and trade system or carbon tax might affect greenhouse gas emissions from the transportation sector. Pricing carbon can influence emissions from the transportation sector in a number of ways. On the firm side, a positive carbon price incentivizes firms to reduce lifecycle emissions from liquid fuels either through the refining process or by switching to fuels that have a lower carbon content. Pricing carbon also incentivizes automobile manufacturers to change their product mix. On the consumer side, pricing carbon differentiates fuels by their carbon content, so consumers have an incentive to switch to cleaner gasoline or alternative fuels. Consumers also have an incentive to drive more efficiently and to keep their vehicles operating more efficiently. The scrapping decisions of consumers are also affected. High mileage vehicles may stay on the roader longer as they become relatively more valuable, while low mileage vehicles may exist faster. New vehicle decisions are also likely to change as consumers switch to more fuel efficient vehicles. Finally, driving habits and trip decisions may also be affected, reducing the number of miles vehicles are driven.

Existing work has focused on the extensive margin by estimating how changes in gas prices affect what new cars people purchase and how scrappage decisions change. Using a single unique data source, we focus on two influences: scrappage decisions and vehicle miles travelled. We both summarize recent empirical work and present new results.

We bring together a number of unique data sets. The first is the universe of test records for California's emissions inspection and maintenance program, so-called smog tests, for the period of 1996 to 2009. California requires vehicles older than six years to receive biennial testing. In addition, testing occurs each time a vehicle changes ownership and randomly for a small share of vehicles. Among other things, the inspection data report odometer readings, which we use to measure vehicle miles travelled between tests. To measure greenhouse gas emissions, we link these 
data to EPA fuel economy ratings. In addition, the data are linked to EIA gas prices for the same years.

Our work builds on a recent literature analyzing how changes in gasoline prices influence consumer behavior. On the extensive margin, Busse, Knittel, and Zettelmeyer (2009) study purchase decisions and dealer pricing decisions using transaction-level data for both new and used vehicles. They find that increased gasoline prices influence both which vehicles consumers buy and the prices they pay for them in both the new and used vehicle markets. Furthermore, market shares are most influenced in the new vehicle market, while prices are most affected in the used market. Using model-level registration data for twenty MSAs, Li, Timmins, and von Haefen (2009) finds higher gas prices affect both new vehicle purchase decisions and used vehicle scrapping decisions. Hughes, Knittel, and Sperling (2008) estimate the short run elasticity for gasoline and find that over time elasticities have fallen.

Most of these papers use monthly variation in gasoline prices for their empirical results. Therefore, their results are short run in nature. One of the contributions of this paper is that because of the richness of our data, in particular a large number of individual decisions that take place through out the year, we are able to estimate how changes in gas prices affect decisions that take place within two-year intervals. That is, our empirical models estimate how miles driven decisions over a two-year period are affected by changes in the average gas price throughout this entire period. We are able to estimate this longer run elasticity because observe many two-year intervals within our sample. To estimate a "two-year elasticity" with aggregate data would require a much larger time series than we require.

The paper proceeds as follows. Section 2 discusses the empirical setting. The data are discussed in Section 3. Section 4 provides graphical support for the two channels, while Section 5 presents the empirical models and results. Finally, Section 6 concludes the paper.

\section{Empirical Setting}

Our empirical setting is California. Our primary data source is the universe of test data from California's Smog Check program from 1996 to 2010. California implemented its first inspection and maintenance program in 1984 in response to the 1977 Clean Air Act amendments. The initial incarnation of the Smog Check program relied purely on a decentralized system of privately run, 
state-licensed inspection stations, and was plagued by cheating and lax inspections. Although the agreement between California and the federal EPA promised reductions in hydrocarbon and carbon monoxide emissions of more the 25 percent, estimates of actual reductions of the early Smog Check Program range from zero to half that amount (Glazer, Klein, and Lave (1995)).

The 1990 Clean Air Act amendments required states to implement an enhanced inspection and maintenance program in areas with serious to extreme non-attainment of ozone limits. Several of California's urban areas fell into this category, and in 1994, a redesigned inspection program was passed by California's legislature after reaching a compromise with the EPA. The program was updated in 1997 to address consumer complaints, and fully implemented by 1998. Among other improvements, California's new program introduced a system of centralized "Test-Only" stations and an electronic transmission system for inspection reports. ${ }^{1}$ Today, more than a million Smog Checks take place each month.

An automobile appears in our data for a number of reasons. First, vehicles that are older than four years old must pass a smog test within 90 days of any change in ownership. Second, in parts of the state (details below) an emissions inspection is required every other year as a pre-requisite for renewing the registration on the vehicle for vehicles that are seven years or older. Third, a small share of vehicles are randomly tested. Fourth, a test is required if a vehicle moves from out-of-state. Finally, some vehicles are flagged as matching a High Emitter Profile (HEP) and must receive a Smog Check every year before registering. Vehicles which fail an inspection must be repaired and receive another inspection before they can be registered and driven in the state. There is also a group of exempt vehicles. These are: vehicles of 1975 model-year or older, hybrid and electric vehicles, motorcycles, diesel powered vehicles and large trucks powered by natural gas.

Since 1998, the state has been divided into three inspection regimes (recently expanded to four), the boundaries of which roughly correspond to the jurisdiction of the Regional Air Quality Management Districts. "Enhanced" regions, designated because they fail to meet state or federal standards for carbon monoxide ( $\mathrm{CO}$ ) and ozone, fall under the most restrictive regime. All of the state's major urban centers are in Enhanced areas, including the greater Los Angeles, San Francisco, and San Diego metropolitan areas. Vehicles that are seven years or older that are registered to an address in an Enhanced area must pass a biennial Smog Check in order to be registered, and they must take the more rigorous Acceleration Simulation Mode (ASM) test, which involves the use of a

\footnotetext{
${ }^{1}$ For more detailed background see http://www.arb.ca.gov/msprog/smogcheck/july00/if.pdf.
} 
dynamometer. In addition, a randomly selected two percent sample of all vehicles in these areas is directed to have their Smog Checks at so-called Test-Only stations, which are not allowed to make repairs. HEP vehicles are also directed to Test-Only stations, as are vehicles which are flagged as "gross polluters" (this occurs when a vehicle fails an inspection with twice the legal limit of one or more pollutant in its emissions). More recently some "Partial-Enhanced" areas have been added, where a biennial ASM test is required, but no vehicles are directed to Test-Only stations.

Areas with air pollution that does not exceed legal limits fall under the Basic regime. Cars in a Basic area must have biennial Smog Checks as part of registration, but they are allowed to take the more lax Two Speed Idle (TSI) test, and no vehicles are directed to Test-Only stations. The least restrictive regime, consisting of rural mountain and desert counties in the east and north of the state, is known as the Change of Ownership area. As the name suggests, inspections in these areas are only required upon change of ownership; no biennial Smog Check is required.

\section{Data}

Our data come from the Bureau of Automotive Repair (BAR) and are the universe of smog tests from 1996 to 2010 and report the location of the test, the vehicle's VIN, odometer reading, the reason for the test, and test results. We decode the VIN to obtain the vehicles' make, model, engine and transmission. Using this, we match the vehicles to EPA data on fuel economy. Because the VIN decoding only holds for vehicles made after 1981, our data are restricted to these models, although to date we have only matched the EPA data for model years 1984 to the present. We also restrict our sample to 1998 and beyond given the large changes that occurred in 1997. This yields roughly 120 million observations. For the analysis in this paper we use a random 10 percent sample.

For biennial tests, we construct the average gasoline price between the two test data using EIA's national average prices.

\section{Initial Evidence}

Before discussing the econometric models and results, we provide graphical evidence suggesting that increasing fuel prices affects both the intensive and extensive margins. 


\subsection{Extensive Margin}

Changes in the extensive margin will manifest themselves in changing the mix of vehicles that are registered through both scrappage and new vehicle sales. We present evidence of both. Figure 1 plots both gas prices and the average fuel economy of newly registered vehicles within one year of the current year. While the Smog Test program does not require dealers to test new vehicles, tested vehicles within one year of the current year are likely to correlated well with new vehicle sales as we are capturing changes in ownership and vehicles moving into California that are one or two years old. ${ }^{2}$

From 1998 to 2004, there was a steady decrease in the fuel economy of new vehicles registered in California. This corresponds to the increase in SUV sales and a period of relatively low gasoline prices. As gasoline prices rose, however, this trend reversed. Remarkably, the trend again reversed as gasoline prices began to fall in 2008. We take this as evidence, consistent with Busse, Knittel, and Zettelmeyer (2009) that new vehicle sales respond to gasoline prices. Indeed, this figure extends their analysis to include the drop in gasoline prices beginning in 2008.

As evidence that scrappage rates respond to gasoline prices, we plot the average fuel economy of vehicles of a specific model year over time. If the scrappage rates of vehicles of a specific vintage are independent of a vehicle's fuel economy or gasoline prices, then the average fuel economy of a particular model-year over time will be constant. There is reason to believe, however, that less fuel efficient vehicles have lower hazard rates since trucks typically last longer than passenger cars. ${ }^{3}$

Figure 2 plots the average fuel economy of vehicles with model years of 1984, 1986, 1988, and 1990 being tested as part of either the random or biennial test programs, as well as gasoline prices. The model years are old enough to be at risk of scrappage and required biennial Smog Checks in each year of our data. All four model years, early in the sample, show a general decreasing trend in fuel economy, consistent with the higher durability of low fuel economy vehicles. This trend continues even as gasoline prices begin to rise in 2003. However, this trend appears to break and in three of the four cases reverse the higher are gasoline prices.

\footnotetext{
${ }^{2}$ The graphs in this section smooth the series using a lowess smoothed line with a bandwidth equal to four months.

${ }^{3}$ Therefore, all else equal, we might expect the average fuel economy of a given model year to fall over time. See, for example, $\mathrm{Lu}$ (2006) which finds different scrappage rates for cars and trucks.
} 


\subsection{Intensive Margin}

We present preliminary evidence that gasoline prices affect the intensive margin by plotting monthly gas prices and the average miles driven (VMT) daily within a year (Figure 3). The figure suggests that VMT rose from 1998 to 1999 and then began a steady decline. This corresponds to the period where gasoline prices began to rise. We also see a small increase in VMT during 2009, which corresponds to the decrease in gasoline prices, albeit with some lag. Figure 4 plots the distribution of VMT in 1998 and 2008. The figure suggests an entire shift in the distribution over this time period.

\section{$5 \quad$ Empirical Models and Results}

\subsection{Extensive Margin}

Our first empirical model, estimates the hazard rate of the decision to scrap a vehicle as a function of the cost per mile of the vehicle. We define a vehicle as being scrapped if it had a biennial smog test in year $X$, but does not have another smog test by year $X+3$. We estimate a stratified discrete time Cox proportional hazard model. The stratified model allows the baseline hazard to vary by groups, where we define groups by either the make of the vehicle or the specific make/model/engine/drivetrain/transmission. We also include a sixth-order polynomial in the vehicle's odometer, whether the vehicle previously failed a smog test, whether it was flagged as a gross polluter, and separate vintage fixed effects for cars and trucks.

The key covariate is a vehicle's cost per mile during the period after a biennial smog test. We calculate the average gasoline price for the two years after the vehicle took the test and divide this by its fuel economy rating. As gasoline prices increase, the cost of operating all vehicles increase. All else equal, this will tend to increase the hazard rate for all vehicles. However, there is also a more general equilibrium effect. Busse, Knittel, and Zettelmeyer (2009) find that prices for fuel efficient vehicles increase as gasoline prices increases. This implies that as gasoline prices increase the "continuation value" of fuel efficient vehicles might also increase, despite their increase in usage costs. This may reduce the scrapping rates of these vehicles. For this reason, we separate the effect of change in cost per mile by fuel efficiency quartile.

While our data are rich, one shortcoming of our data is that a vehicle can exit our data for a number of reasons. For one, it might be retired while still capable of being used; the decision of 
interest. Second, it could have been scrapped as a result of an accident. Third, it might move to a county that does not require smog tests. Finally, it might leave the state. These final three reasons for exit present a difficulty for us. Insofar as they are correlated with gas prices, we will tend to over or under predict the effect of changes in gas prices on scrappage decisions. Below we discuss empirical evidence that suggests our results are likely lower bounds on how increases in gasoline prices increase fleet fuel economy by changing the scrappage decisions of owners of existing vehicles.

Table 2 reports the results. Model 1 estimates the scrappage of vehicles that are over 15 years old and includes only the dollars per mile of the vehicle as the key regressor along with a dummy for whether the vehicle is a truck, the polynomial in the odometer reading, year fixed effects, vintage fixed effects and make fixed effects. Model 2 splits the effect of dollars per mile by the whether the vehicle falls in the first, second, third, or fourth fuel economy quartile. ${ }^{4}$ Because these coefficients represent changes in the baseline hazard, coefficients smaller than one represent decreases in the probability of scrappage when the respective variable increases.

Both Models 1 and 2 suggest that increases in the per mile cost of driving reduces the chances a vehicle is scrapped. Specifically, Model 1 suggests that a 5 cent increase in the cost per mile of driving reduces the chances all vehicles are scrapped by roughly 12 percent. When we split this effect by fuel economy quartile, there is some evidence that this effect is strongest for the top three fuel economy quartiles. That is, low fuel efficient vehicles become relatively more likely to be scrapped.

There are at least two explanations for why higher gas prices may lower the likelihood a vehicle is scrapped. First, there may be an income effect, in the sense that as gas prices increase vehicles stay on the road longer as consumers have less disposable income to buy newer vehicles. Second, and somewhat related, the propensity to sell a vehicle might fall as gas prices increase. As noted above, because in our data "scrappage" will also capture vehicles moving from counties that require smog checks to those that don't, as such as the number of transactions fall, this will be expressed as a reduction in scrappage. We find evidence of this when looking at the probability of being "scrapped" of vehicles between 6 and 9 years old. For these vehicles, as gas prices increase their probability of being scrapped, where scrappage likely reflects the chances of being sold to a county that does not require a smog test, falls. Given this, we view these estimates as lower bounds on how gas prices affects the retirement decisions of our at-risk category.

\footnotetext{
${ }^{4}$ We define the quartiles across the entire sample, but the results are robust to defining them within year as well.
} 
The first two models only allow the baseline hazard to depend on make, vintage and whether the vehicle is a car or truck. Within a make, there is a lot of heterogeneity in terms of the longevity of a vehicle within manufacturer and model year. To account for this, the last two models stratify by make, model, model year, engine, and transmission.

Model 3 constrains the dollar per mile effect to be constant across fuel efficiencies. The results are similar to model 1. However, when we allow the cost effect to differ by fuel-efficiency quartile, we find much larger heterogeneity. In addition despite the likelihood that the level of these effects are likely biased downward, we find that as gas prices increase the lowest fuel efficiency quartile vehicles are more likely to be scrapped. While the highest fuel efficient vehicles are much less likely to be scrapped compared to model 2.

We note that the right hand side variable is the dollars per mile, therefore the fact that we find heterogeneity across fuel efficiency quartiles implies that to incentivize a low fuel efficiency vehicle to exit requires a smaller change in gasoline prices than a high fuel efficiency vehicle. To put these estimates into perspective, the average fuel efficiency of a bottom quartile vehicle is 16.7 MPG. A one dollar increase in gasoline prices increases the cost per mile of these vehicles by roughly 6 cents. Therefore, because our coefficients are scaled for a 5 cent change in the cost per mile, a one dollar increase in gas prices increases the chance a bottom quartile vehicle is scrapped by approximately 15 percent. ${ }^{5}$ The average fuel efficiency of a fourth quartile vehicle is $30.3 \mathrm{MPG}$, implying a one dollar increase in gas prices, increases the cost per mile of these vehicles by 3.3 cents. Therefore a one dollar increase in gas prices reduces the chances a top-quartile vehicle is scrapped by roughly 45 percentage point.

\subsection{Intensive Margin}

We next estimate how gasoline prices affect the intensive margin. To do this, we calculate the change in the odometer reading between biennial tests for each vehicle and the average gasoline prices during the two years between tests. This leaves roughly 1.8 million observations in our 10 percent sample.

As with the hazard model, we vary the set of fixed effects included. The key independent variable is either the log of gasoline prices (Table 3) or the of log dollars per mile (Table 4). Model

\footnotetext{
${ }^{5}$ Again, the Cox model is not linear, but for small changes around coefficients scaled for a 5 cent change the error is likely small.
} 
1 in Table 3 includes just year fixed effects, vintage fixed effects and a truck indicator variable. The results suggest a VMT elasticity of 0.442 . It is important to note that while we are using within year variation in gasoline prices, because we are estimating the effect of a 1 percent change in gasoline prices over the entire two year period, these estimates represent fairly long run elasticity. We believe that this makes these results unique in the sense that the individual level data allow us to estimate long run elasticities without aggregating the time series of the data (e.g., this would be infeasible if use average yearly California consumption over a two-year period). Because of this, these estimates are larger than recent estimates of short run elasticities (e.g., Hughes, Knittel, and Sperling (2008)). Model 2 adds manufacturer fixed effects to Model 1. The results change very slightly. Model 3 allows the elasticity to vary by fuel efficiency quartile and finds very similar results across quartiles.

Models 4 and 5 include make/model/engine/model year fixed effects. The average elasticities changes very little, but a significant amount of heterogeneity exists. The top quartile vehicles' elasticity is less than half that of bottom quartile vehicles. One potential explanation for this is that we observe within household substitution from the fuel inefficient vehicles to the fuel efficient vehicles. We are exploring this in current work. ${ }^{6}$ Another potential explanation is that a given change in gasoline prices implies a larger change in the cost per mile for fuel inefficient vehicles. But, we note that the rich fixed effects in Models 4 and 5 imply that we are looking within vehicle type. Indeed, Table 4 suggests that when we do not account for the vehicle type (Models 2 through 3) the results with the $\log$ of gasoline prices and the log of cost per mile differ considerably. ${ }^{7}$

\section{Conclusions}

This paper estimates how changes in gasoline prices effect both the extensive and intensive margins of automobile use. We find significant effects on scrapping decisions, new vehicle purchase decisions, and miles travelled. The results highlight the variety of avenues through which carbon pricing policies may affect emissions from the transportation sector.

\footnotetext{
${ }^{6}$ This is consistent with the household bargaining that took place for one of the authors.

${ }^{7}$ Because they include vehicle-type fixed effects, Models 4 and 5 are identical across the two specifications.
} 


\section{References}

Busse, M., C. R. Knittel, and F. Zettelmeyer (2009): "Pain at the Pump: The Differential Effect of Gasoline Prices on New and Used Automobile Markets," Discussion paper, National Bureau of Economic Research, Cambridge, MA.

Glazer, A., D. B. Klein, and C. Lave (1995): "Clean on Paper, Dirty on the Road: Troubles with California's Smog Check," Journal of Transport Economics and Policy, 29(1), 85-92.

Hughes, J. E., C. R. Knittel, and D. Sperling (2008): "Evidence of a Shift in the Short-Run Price Elasticity of Gasoline Demand," Energy Journal, 29(1).

Li, S., C. Timmins, and R. H. von Haefen (2009): "How Do Gasoline Prices Affect Fleet Fuel Economy?," American Economic Journal Economic Policy, 1(2).

Lu, S. (2006): "Vehicle Survivability and Travel Mileage Schedules," Working Paper DOT HS 809 952, NHTSA Technical Report. 


\section{Appendix}

\section{$1 \quad$ Figures}

Figure 1: Average Fuel Economy of New Vehicles Registered in California

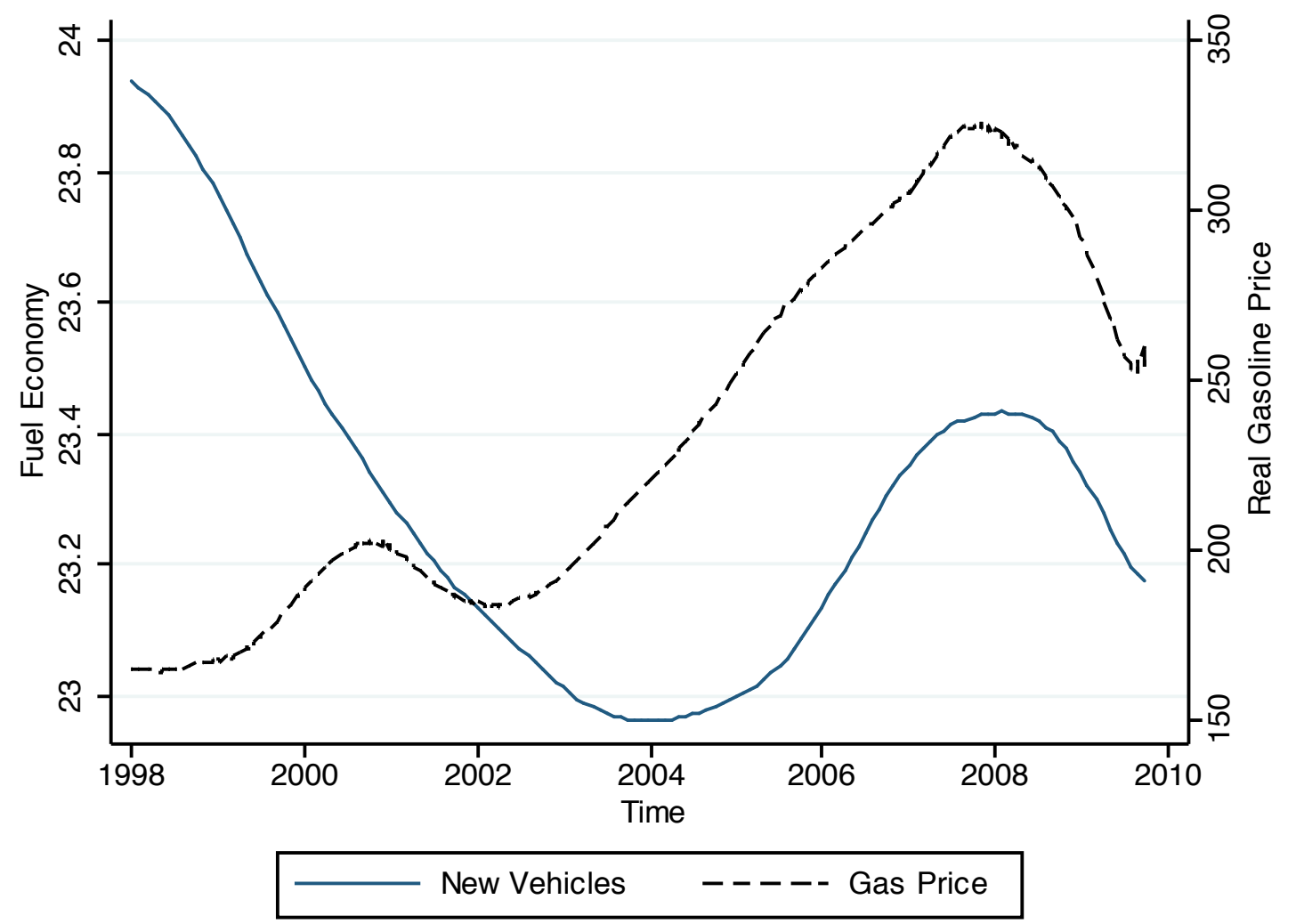


Figure 2: Average Fuel Economy for Vehicles with Model Years of 1984, 1986, 1988, and 1990 over Time
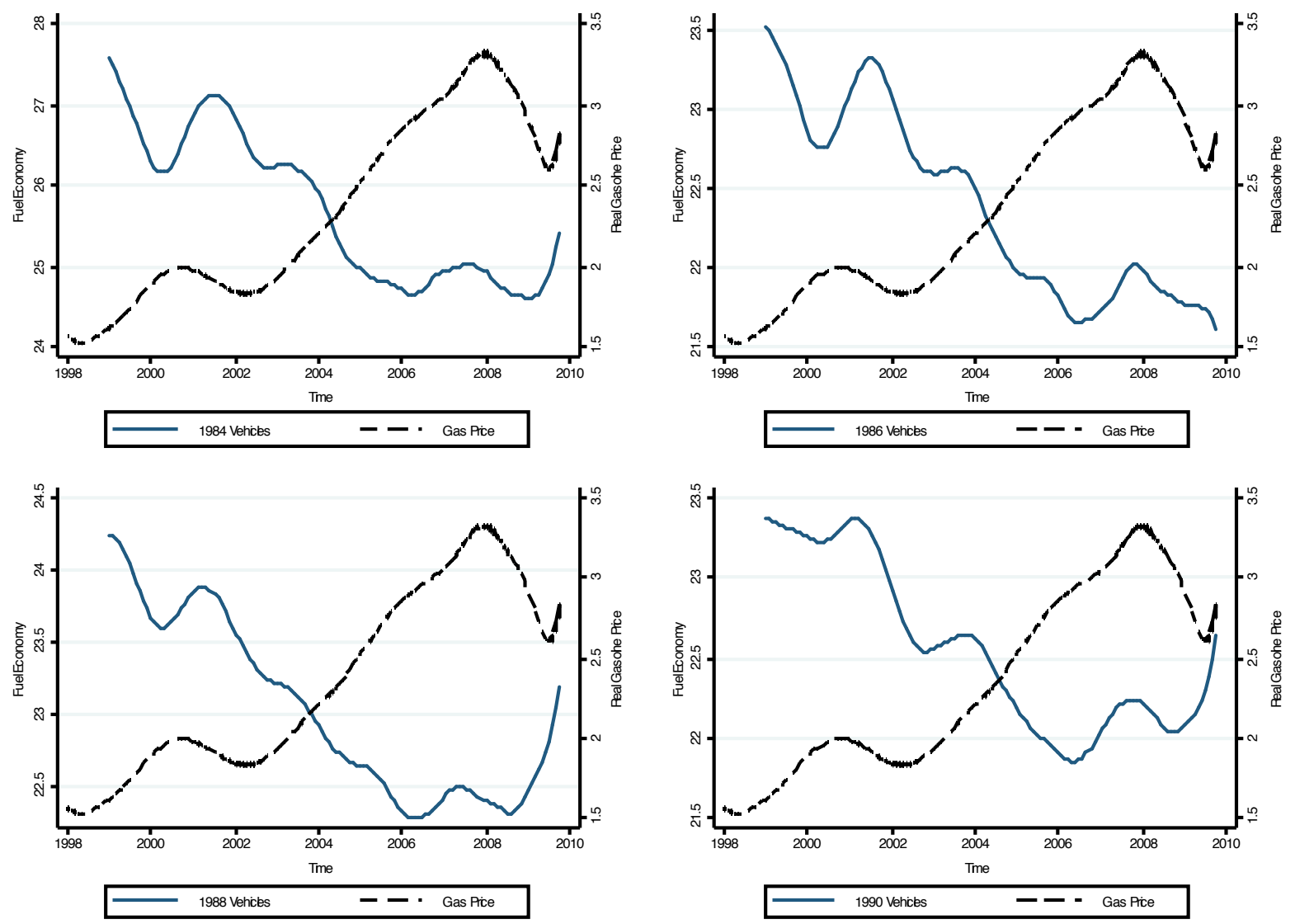
Figure 3: Average Miles Driven per Day and Gasoline Prices

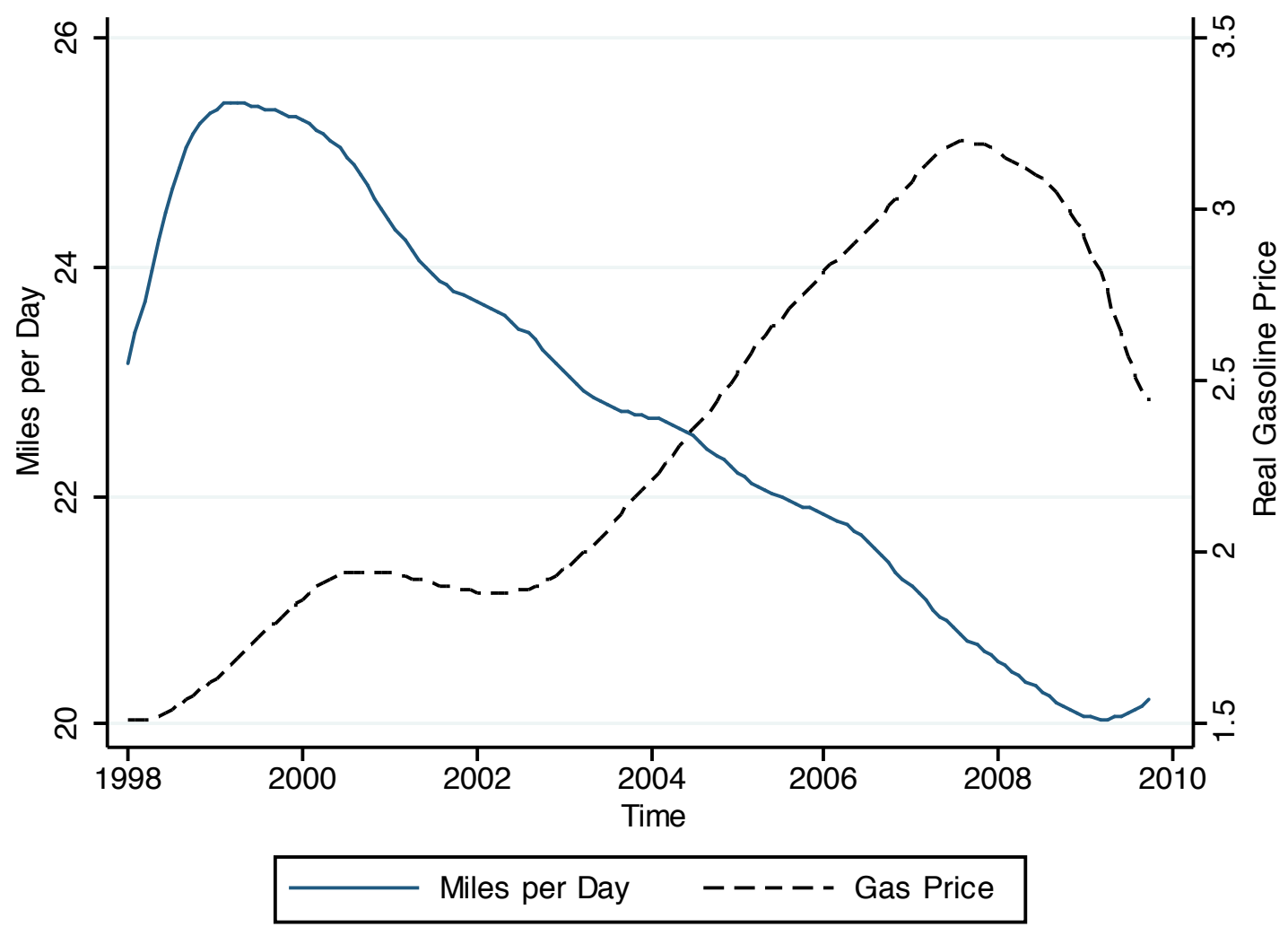


Figure 4: Distribution of Miles Driven per Day in 1998 and 2008

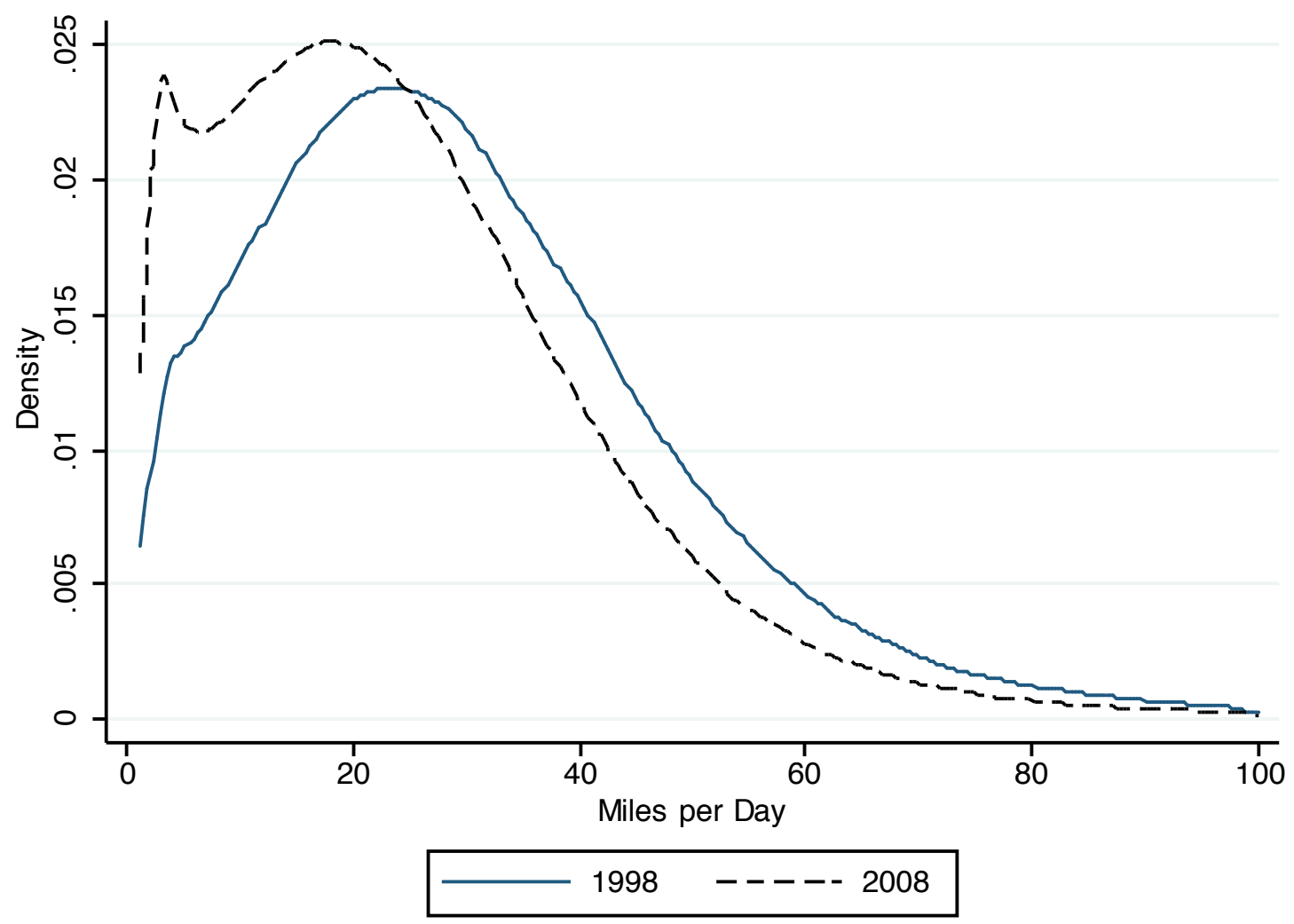




\section{Tables}

\begin{tabular}{cccccc}
\hline Year & Count & MPG & VMT/day & Gasoline Price & Cents/Mile \\
\hline \hline 1998 & 661,729 & 23.92 & 33.42 & 1.52 & 7.31 \\
1999 & 512,168 & 23.98 & 34.62 & 1.75 & 7.74 \\
2000 & 869,975 & 23.78 & 30.84 & 2.09 & 8.45 \\
2001 & 791,347 & 23.77 & 31.95 & 1.95 & 8.48 \\
2002 & 788,716 & 23.56 & 29.40 & 1.82 & 8.49 \\
2003 & 809,615 & 23.45 & 30.30 & 2.04 & 9.30 \\
2004 & 1119371 & 23.29 & 28.07 & 2.38 & 10.59 \\
2005 & 833,477 & 23.30 & 28.88 & 2.71 & 12.02 \\
2006 & 953,961 & 23.17 & 27.23 & 3.02 & 13.33 \\
2007 & 877,855 & 23.16 & 27.32 & 3.10 & 14.27 \\
2008 & 959,873 & 23.05 & 25.84 & 3.71 & 14.73 \\
2009 & 799,774 & 23.06 & 26.27 & 2.45 & 14.37 \\
\hline
\end{tabular}

Table 1: Means of Greenhouse Gas Emission-related Variables 


\begin{tabular}{|c|c|c|c|c|}
\hline & Model 1 & Model 2 & Model 3 & Model 4 \\
\hline \multirow[t]{2}{*}{ Dollars per Mile } & $0.882 * *$ & & $0.872 * *$ & \\
\hline & $(0.005)$ & & $(0.024)$ & \\
\hline \multirow[t]{2}{*}{ Dollars per Mile * MPG Quartile 1} & & $0.862 * *$ & & $1.119 * *$ \\
\hline & & $(0.007)$ & & $(0.034)$ \\
\hline \multirow[t]{2}{*}{ Dollars per Mile * MPG Quartile 2} & & $0.841 * *$ & & $0.892 * *$ \\
\hline & & $(0.009)$ & & $(0.028)$ \\
\hline \multirow[t]{2}{*}{ Dollars per Mile * MPG Quartile 3} & & $0.837 * *$ & & $0.592 * *$ \\
\hline & & $(0.010)$ & & $(0.021)$ \\
\hline \multirow[t]{2}{*}{ Dollars per Mile * MPG Quartile 4} & & $0.840 * *$ & & $0.314 * *$ \\
\hline & & $(0.012)$ & & $(0.014)$ \\
\hline \multirow[t]{2}{*}{ Truck } & $0.778 * *$ & $0.776 * *$ & $0.815^{* *}$ & \\
\hline & $(0.005)$ & $(0.005)$ & $(0.041)$ & \\
\hline \multirow[t]{2}{*}{ Odometer } & 0.936 & 0.936 & 0.927 & 0.925 \\
\hline & $(0.054)$ & $(0.054)$ & $(0.057)$ & $(0.057)$ \\
\hline \multirow[t]{2}{*}{ Odometer2 } & $1.560 * *$ & $1.557 * *$ & $1.607 * *$ & $1.607 * *$ \\
\hline & $(0.076)$ & $(0.076)$ & $(0.084)$ & $(0.084)$ \\
\hline \multirow[t]{2}{*}{ Odometer3 } & $0.816^{* *}$ & $0.817 * *$ & $0.806^{* *}$ & $0.806^{* *}$ \\
\hline & $(0.015)$ & $(0.015)$ & $(0.016)$ & $(0.016)$ \\
\hline \multirow[t]{2}{*}{ Odometer4 } & $1.037 * *$ & $1.037 * *$ & $1.039 * *$ & $1.039 * *$ \\
\hline & $(0.003)$ & $(0.003)$ & $(0.004)$ & $(0.004)$ \\
\hline \multirow[t]{2}{*}{ Odometer5 } & $0.997 * *$ & $0.997 * *$ & $0.997 * *$ & $0.997 * *$ \\
\hline & $(0.000)$ & $(0.000)$ & $(0.000)$ & $(0.000)$ \\
\hline \multirow[t]{2}{*}{ Odometer6 } & $1.000 * *$ & $1.000 * *$ & $1.000 * *$ & $1.000 * *$ \\
\hline & $(0.000)$ & $(0.000)$ & $(0.000)$ & $(0.000)$ \\
\hline \multirow[t]{2}{*}{ Gross Polluter } & $1.127 * *$ & $1.126^{* *}$ & $1.099 * *$ & $1.103 * *$ \\
\hline & $(0.016)$ & $(0.016)$ & $(0.017)$ & $(0.017)$ \\
\hline \multirow[t]{2}{*}{ Failed in the Past } & $1.491 * *$ & $1.488 * *$ & $1.409 * *$ & $1.383 * *$ \\
\hline & $(0.016)$ & $(0.016)$ & $(0.016)$ & $(0.016)$ \\
\hline \multirow[t]{2}{*}{ Time Trend } & $1.001+$ & 1.000 & $1.021 * *$ & $1.020 * *$ \\
\hline & $(0.000)$ & $(0.000)$ & $(0.000)$ & $(0.000)$ \\
\hline \multirow[t]{2}{*}{ Time Trend Squared } & $1.000 * *$ & $1.000 * *$ & $1.000 * *$ & $1.000 * *$ \\
\hline & $(0.000)$ & $(0.000)$ & $(0.000)$ & $(0.000)$ \\
\hline Vintage Fixed Effects & Yes & Yes & Yes & Yes \\
\hline Stratified on Make & Yes & Yes & -- & -- \\
\hline Stratified on VIN Prefix & No & No & Yes & Yes \\
\hline Observations & 676321 & 676322 & 676323 & 676324 \\
\hline
\end{tabular}

Table 2: Probability of Exit as a Function of Gasoline Prices - Cox Proportional Hazard Model 


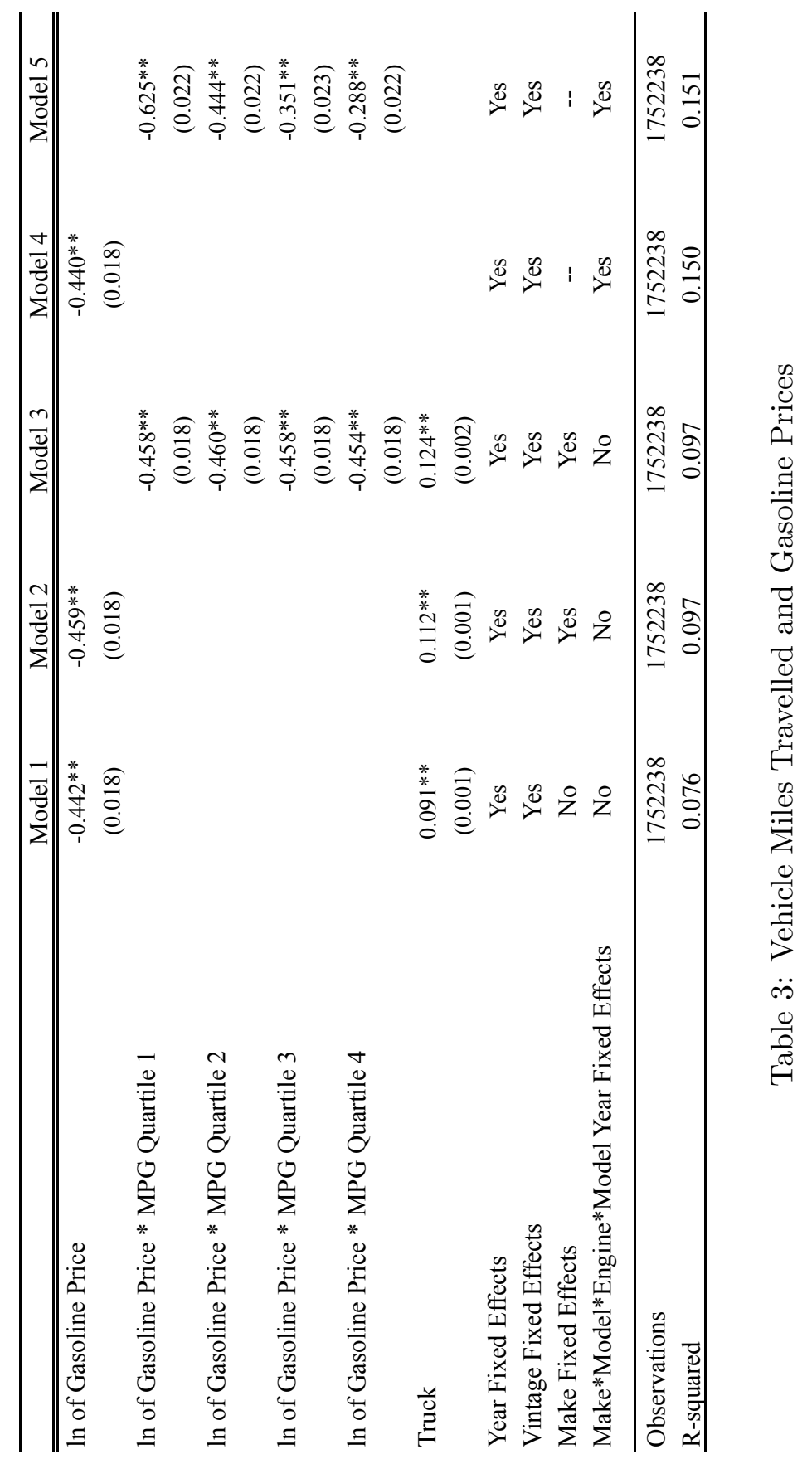




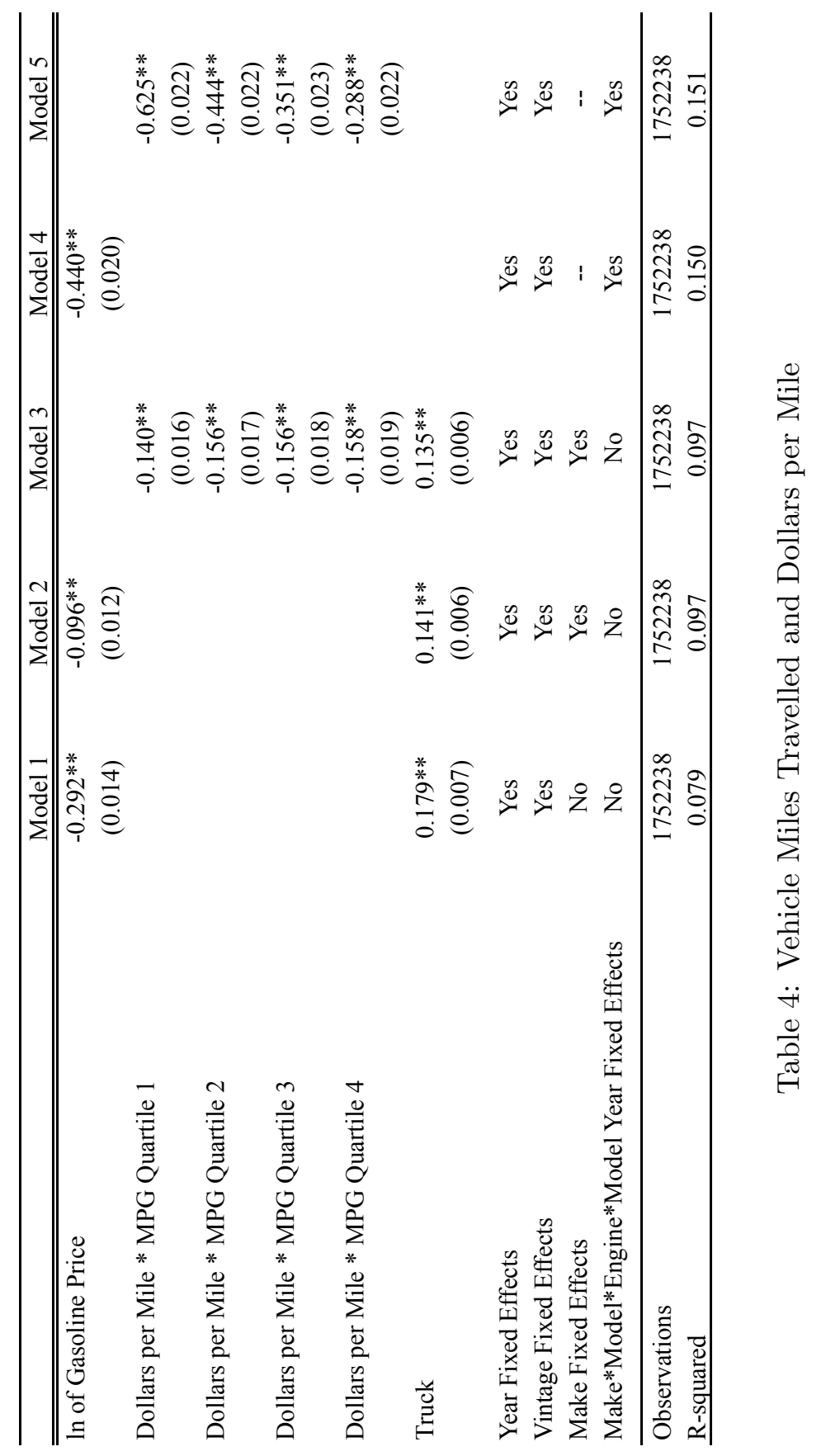

